\title{
Tunçbilek Linyitinin Sorgum Biyokütlesi ve Biyokütle Hidrolizatı ile Birlikte Gazlaştırılması
}

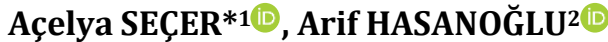 \\ 1,2Çukuova Üniversitesi, Fen Edebiyat Fakültesi, Kimya Bölümü, 01330, Adana, Türkiye
}

(Alınış / Received: 12.09.2019, Kabul / Accepted: 24.02.2020, Online Yayınlanma / Published Online: 20.04.2020)

Anahtar Kelimeler

Kömür,

Biyokütle,

Gazlaştırma,

Birlikte gazlaștırma,

Hidrojen
Özet: Bu çalışmada, yüksek oranda kükürt $(\% 1,2)$ ve kül $(\% 20,6)$ içeren Tunçbilek linyiti, öğütülmüss katı sorgum (green go) ve sub-kritik su koşullarında hidroliz edilmiş sorgum hidrolizatı ile birlikte gazlaştırılarak gaz ürün dağılımı ve birlikte gazlaştırma işlemine sorgumun sinerjik etkisi incelenmiştir. Ögütülmüş katı sorgum ve sorgum hidrolizatı ile yapılan birlikte gazlaştırma deneylerinden elde edilen gaz hacimleri, Tunçbilek linyitinin tek başına gazlaştırılmasından elde edilenden daha fazla olduğu görülmüștür. En yüksek toplam gaz hacmi $(2810 \mathrm{~mL})$ ve hidrojen verimi $(\% 70,1) 900{ }^{\circ} \mathrm{C}$ sıcaklıkta sorgum hidrolizatı ile yapılan birlikte gazlaştırma deneylerinden elde edilmiştir.

\section{Co-gasification of Tunçbilek Lignite with Sorghum Biomass and Sorghum Biomass Hydrolysate}

\section{Keywords}

Coal,

Biomass,

Gasification,

Co-gasification,

Hydrogen

\begin{abstract}
In this study, high sulphur (1.2\%) and ash (20.6\%) containing Tunçbilek lignite was co-gasified with raw sorghum (green go) biomass and sorghum hydrolysate, which was hydrolyzed under sub-critical conditions, and synergetic effects of sorghum on co-gasification process were investigated as well as product distributions. The total gas volume obtained from individual gasification of Tunçbilek lignite was less than those obtained from both co-gasification with raw Sorghum and Sorghum hydrolysate. The highest total gas $(2810 \mathrm{~mL})$ and hydrogen yield $(70.1 \%)$ was obtained from co-gasification with sorghum hydrolysate.
\end{abstract}

\section{Giriş}

Dünya enerji ihtiyacının yaklaşık \%29'u hala kömür tarafından karşılanmakta ve elektriğin \%40'ı da kömür kullanılarak üretilmektedir [1]. Bu nedenden ötürü, kömür hala dünyanın ana enerji kaynağı olarak kullanılmaya devam etmektedir. Kullanımı sonucu yarattığı çevresel sorunlar ve daha temiz enerji formlarına geçiş çalışmaları kömür kullanımı açısından zorluklar ve rekabet doğuruyor olsa da mevcut kömür rezervlerinin miktarları, diğer kaynaklardan üretilen enerjilerin üretim maliyetleri, enerji kaynaklarının kullanım miktarları ve bu istatistiklerin geleceğe yönelik ekstrapolasyonları, kömürün bir süre daha ana enerji kaynakları arasında yerini koruyacağını göstermektedir [2]. Bu noktada doğru soru, bu dezavantajları azaltarak kömürden nasıl daha temiz enerji elde edilebileceğidir. Dolayısıyla, kömür alandaki araştırmalar özellikle mevcut işleme teknolojilerinde daha temiz yöntemler geliştirmeye odaklanmaktadır. Gazlaştırma, kömürün daha temiz bir şekilde işlenebileceği alternatif bir teknolojidir. Bu yöntemde kömür, $\quad 800 \quad{ }^{\circ} \mathrm{C}$ 'nin üzerindeki reaksiyon sıcaklıklarında buhar, hava ve / veya oksijen, karbon dioksit veya bu gazların bir karıșımı ile reaksiyona sokularak, öncelikle hidrojen, karbon monoksit, karbon dioksit ve metan içeren bir sentez gazı karıșımına dönüștürülür [3]. Kömür çarının düşük oksidasyon kinetiği nedeniyle tamamlanamayan dönüșümü, kömür gazlaștırma sistemlerinde enerji verimliliği düşmesine neden olmaktadır. Bu nedenle kömür oksidasyon reaksiyonlarının hızlandırılmaları için birtakım katalizörlerin kullanılması gerekir [4]. Alkali ve toprak alkali metal tuzları, geçiş metalleri ve bunların kompozitleri gibi farklı katalizörler katalitik kömür gazlaștırma proseslerinde kullanılmaktadır [5]. Geleceğin yakıtı olarak hidrojen, su buharı gazlaștırma tekniği ile kömürden üretilebilir [6, 7]. Alkali metal tuzları (özellikle potasyum), 1970'lerden bu yana karbondan hidrojen üretiminde yaygın katalizörler olarak kullanılmaktadır [8]. Biyokütle, yapısında doğal olarak alkali ve alkali toprak metal tuzları bulundurur. Biyokütle ve kömür birlikte 
gazlaştırılması, biyokütlenin içerdiği minerallerin yarattığı sinerjik etkilerden kaynaklı, kömür gazlașma reaksiyonlarını hızlandırmak ve kömürden hidrojen üretimini artırmak için umut verici bir teknolojidir $[9,10]$. Kömürün metal karbonatlarla su buharı varlığında gazlaştırılması sırasında gerçekleşen olası kataliz reaksiyonları çeşitli yazarlar tarafından önerilmiş $[11,12]$ ve basit bir birlikte gazlaștırma reaksiyon șeması da Pan ve arkadaşları tarafından ortaya konmuştur [13]. Farklı türde kömürlerin biyokütle ile birlikte gazlaștırılmasında gözlenen sinerjik etkiler çeşitli çalışmalarla incelenmiștir [13-20]. Bu etkiler, proses enerji verimliliğini, gazlaştırma verimlerini ve elde edilen sentez gazının kompozisyonunu etkileyen çeşitli faktörlere bağlıdır [21]. Biyokütle türü, operasyon sıcaklığı, gazlaştırıcı tipi, kömür/biyokütle bileşim oranı ve buhar ve / veya hava oranı gibi çeşitli faktörlerin birlikte gazlaştırmaya yaptığı etkilerin incelendiği çalışmalar literatürde mevcuttur [19-38].

Lignoselülozik biyokütle, doğada bulunma sıklığl, düşük üretim maliyetleri ve yüksek enerji üretilebilir içeriği nedeni ile enerji üretiminde kullanılması umut verici bir materyaldir. Ancak, kimyasal yapısı oldukça karmaşıktır ve bu yapının parçalanması için bazı ek ön işlemler uygulanması gerekir. Bu yöntemlerden biri, yalnızca su ortamında gerçekleştiği için oldukça çevre dostu bir yöntem olan sub-kritik su ortamında hidrolizdir. Sub-kritik su ortamında, $250 \stackrel{\circ}{\circ} \mathrm{C}$ sıcaklıkta, lignoselülozik biyokütle materyalinin \% 70-75 oranında çözündüğü önceki çalışmalarda bildirilmiştir [39]. Hidroliz edilmiş biyokütle ile kömürün birlikte gazlaştırılması, biyokütle içeriğindeki gazlaşabilir ürün içeriğinin çözündürme yoluyla arttırılması ve katalizör etkisi yaratacak çözünür inorganik tuzların da halen çözelti içinde kalması nedeni ile birlikte gazlaştırma prosesinin performansını arttırabilir.

Dünya linyit rezervlerinin yaklaşık \%1,6'sı Türkiye'de bulunmaktadır. Ancak bu linyitlerin çoğu düşük kalorifik değerlere sahiptir ve bazıları yüksek miktarda kükürt içerir. Bu linyitlerin sentez gazı ve özellikle hidrojen üretimi için gazlaştırılması, bu kömürlerin çevre dostu ve verimli bir şekilde kullanılmasına alternatif bir yaklaşım olabilir. Bu çalışmada kükürt içeriği \% 1,2 (a/a) , kül içeriği \%20,6 olan ve daha önce benzer bir çalışmada kullanılmayan Tunçbilek linyiti, sorgum biyokütlesi ve sorgum biyokütle hidrolizatı ile birlikte gazlaştırılmıștır ve gazlaştırma sonuçları bașta hidrojen verimi olmak üzere elde edilen toplam gaz hacimleri ve gazların içerikleri açısından değerlendirilmiştir. Geleneksel su buharı gazlaştırma yöntemlerinde, su buharı ek bir buhar üretici ünite kullanılarak gazlaştırma sistemine gönderilir. $\mathrm{Bu}$ çalışmada, su buharı, buhar üretici jeneratör ile üretilmek yerine, gazlaştırma sisteme doğrudan gönderilmiştir.

\section{Materyal ve Metot}

\subsection{Materyal}

Bu çalışmada Tunçbilek linyiti ve sorgum (Green go) biyokütlesi kullanılmıştır. Tunçbilek linyitine ve sorgum biyokütlesine ait kısa analiz sonuçları Tablo 1'de verilmiștir. Çalıșmada katalizör olarak susuz sodyum karbonat $\left(\mathrm{Na}_{2} \mathrm{CO}_{3}\right.$, Merck, $\left.\geq 99,9 \%\right)$, demir (III) oksit ( $\mathrm{Fe}_{2} \mathrm{O}_{3}$, Alfa Aesar,20-40nm APS powder), Nikel (II) klörür $\left(\mathrm{NiCl}_{2}\right.$, AlfaAesar, 98\%), kullanılmıştır. Gazlaştırma deneylerinde kullanılan katalizör miktarı, metal içeriği bakımından kuru külsüz bazdaki kömürün \%3'ü olacak şekilde belirlenmiştir.

Tablo 1. Tunçbilek linyiti ve sorgum biyokütlesinin kısa analiz değerleri.

\begin{tabular}{lcc}
\hline & Tunçbilek & Sorgum \\
\hline $\mathrm{C}\left(\mathrm{a} \%, \mathrm{kkb}^{*}\right)$ & 56,0 & 39,8 \\
$\mathrm{H}(\mathrm{a} \%, \mathrm{kkb})$ & 5,2 & 0,8 \\
$\mathrm{~N}(\mathrm{a}, \%, \mathrm{kkb})$ & 2,3 & 5,2 \\
$\mathrm{~S}(\mathrm{a} \%, \mathrm{kkb})$ & 1,2 & - \\
O (a \%) & 35,3 & 54,2 \\
Nem (a \%) & 4,1 & 8,1 \\
Kül (a \%) & 20,6 & 8,4 \\
\hline
\end{tabular}

*Kuru külsüz baz

\subsection{Metot}

\subsubsection{Biyokütlenin Hidrolizi}

Biyokütlenin hidrolizi karbondioksit basıncı altındaki sub-kritik su ortamında gerçekleştirilmiştir. Ögütülmüş $10 \mathrm{~g}$ sorgum, $500 \mathrm{~mL}$ lik reaktör (Parr $4575 \mathrm{HP} / \mathrm{TP}$ ) içinde $350 \mathrm{~mL}$ su ile $250^{\circ} \mathrm{C}$ ve $4060 \mathrm{psi}$ basınçta hidroliz edilmiştir. Hidroliz işleminin ayrıntılarına önceki çalışmalarda yer verilmektedir [39].

\subsubsection{Gazlaştırma ve birlikte gazlaştırma deneyleri}

Tüm gazlaştırma deneyleri sabit yataklı reaktörde gerçekleştirilmiştir. Kömür, sorgum veya 3:1 (a/a) oranında karıștırılan kömür/sorgum karıșımı, toplam gazlaşan madde miktarı kuru külsüz bazda 1,0 g olacak şekilde hazırlanarak çelik reaktöre (iç çap 0,56 ", dış çap 1,4") yerleştirilmiştir. Paslanmaz çelik reaktör bir yüksek sıcaklık fırını içerisinde dakikada $30^{\circ} \mathrm{C}$ artışlarla $900{ }^{\circ} \mathrm{C}$ ye kadar isıtılırken gazlaștırıcı ajan olarak su 0,5 mL dk $\mathrm{dk}^{-1}$ akış hızında reaktöre gönderilmiştir. Hidroliz çözeltisi kullanılarak yapılan gazlaştırma deneylerinde sisteme su yerine $0,5 \mathrm{~mL}$ dk-1 akış hızında hidroliz çözeltisi gönderilmiştir. Kolondan çıkan su gaz karışımı bir ön soğutucudan geçirilerek gaz-sıvı ayırıcı rezervuara giriş yapmıştır. Sıvı kısım bu rezervuarda toplandıktan sonra, gaz karıșımı kadmiyum asetat çözeltisi içinden geçirilmiș ve oluşan $\mathrm{H}_{2} \mathrm{~S}$, CdS şeklinde çöktürülmüştür. $\mathrm{H}_{2} \mathrm{~S}$ haricindeki diğer gazlar bir gaz büretinde toplanmış ve hacmi ölçüldükten sonra oluşan gazın kompozisyonu gaz kromatografisi cihazında analiz 
edilerek saptanmıştır. Gazlaştırma sisteminin şematik gösterimi Şekil 1'de verilmiştir.

Gazlaştırma deneyleri sonunda oluşan gaz karışımlarının bir büret içerisinde toplanarak hacimleri belirlenmiş ve analizleri gerçekleştirilmiştir. Gaz karışımının kalitatif ve kantitatif analizleri, iki kanallı termal elektrik iletkenlik dedektörlü (TCD) Varian-450 gaz kromatografi cihazı ile yapılmıştır. Hidrojen gazı Argon taşıyıcı gazının kullanıldığı kanalda, Varian Restek Molsieve 5A $1 \mathrm{~m} \times 1 / 8$ " kolon ile analiz edilmiştir. Hidrojen gazı hariç diğer gazların analizi, Helyum taşıyıcı gazının kullanıldığı diğer kanalda, Varian Restek Shincarbon 100/120 mesh $2 \mathrm{~m} \times 1 / 16^{\prime \prime} \times 1 \mathrm{~mm}$ kolonda gerçekleştirilmiştir. Kolon firın sicaklık programı, $40^{\circ} \mathrm{C}^{\prime} \mathrm{de} 3 \mathrm{dk}$ bekleme, $8^{\circ} \mathrm{C} \mathrm{\textrm {dk } ^ { - }}$ 1 ile $230{ }^{\circ} \mathrm{C}$ 'ye yükselme ve bu sicaklıkta $5 \mathrm{dk}$ bekleme şeklinde toplam $31,75 \mathrm{dk}$ sürede gerçekleştirilmiştir. Dedektör sıcaklığı $230{ }^{\circ} \mathrm{C}$, filament sıcaklığı ise $300 \stackrel{\circ}{\circ}$ olarak çalışılmıştır. Standart gaz karışımı olarak Elite Gaz Teknolojileri İnş. Tur. San. Tic. Ltd. Şti.'den (İstanbul, Türkiye) sağlanan içerisinde \% mol olarak sirasiyla $1,8 \pm 0,04$ asetilen, $4,0 \pm 0,1$ etilen, $3,9 \pm 0,1$ etan, 4,9 $\pm 0,1$ metan, $16,0 \pm 0,3$ karbonmonoksit, $22,0 \pm 0,4$ karbondioksit ve balans sağlayacak miktarda hidrojen $(47,4 \pm 0,5)$ bulunan gaz karışımı kullanılmıştır.

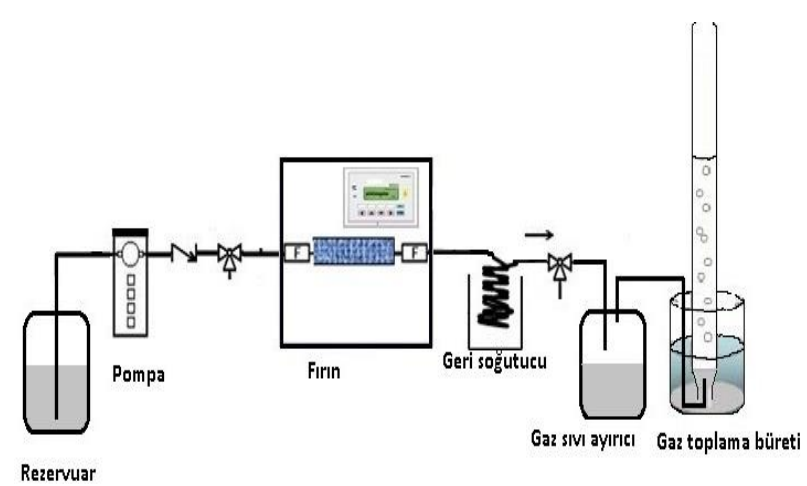

Şekil 1. Gazlaștırma sistemi

\subsubsection{Sıvı ürün analizleri}

Gazlaşma deneyleri sonrasında oluşan sıvı ürünler bir rezervuar kabında toplanarak hacimleri belirlenmiștir. Daha sonra bu sıvı, diklorometan çözücüsü ile ekstrakte edilmiş ve Thermo TR-5MS kapiler kolon $(60 \mathrm{~m} \times 0,25 \mathrm{~mm}$ ID $\times 0,25 \mu \mathrm{m})$ kullanilarak, Thermo Finnigan GC-MS gaz kromatografisi-kütle spektrometresi cihazında analizleri gerçekleştirilmiştir. GC-MS sıcaklık programi: $40^{\circ} \mathrm{C}$ 'de 5 dakika bekledikten sonra 280 ${ }^{\circ} \mathrm{C}^{\prime}$ ye $5{ }^{\circ} \mathrm{C} \mathrm{dk}^{-1}$ lık artışlarla yükselerek bu sıcaklıkta $10 \mathrm{dk}$ bekleme şeklindedir. Ürünlerin içerikleri NIST (National Institute of Standards and Technology) kütle spektral kütüphanesi ile belirlenmiștir.

\section{Bulgular ve Tartışma}

\subsection{Sorgum katı biyokütlesi ile birlikte gazlaştırma}

Çalışmada Tunçbilek linyiti ve sorgum biyokütlesi katalizörlü ve katalizörsüz ortamda tek başına ve birlikte gazlaştırılarak, toplam gaz hacimleri ve gazların bileşimleri açısından değerlendirilmiştir. Gazlaştırma deneyleri, önceki kömür gazlaştırma çalışmalarında etkin değerler olarak belirlenen 0,5 mL dk-1 su akış hızı, $900{ }^{\circ} \mathrm{C}$ sıcaklıkta ve $3: 1$ (g/g) oranında kömür/biyokütle karıșımı kullanılarak [40] gerçekleștirilmiștir. Tüm deneylerden elde edilen gazların içeriği başlıca $\mathrm{H}_{2}$ olmak üzere, $\mathrm{CO}_{2}, \mathrm{CO}$ ve $\mathrm{CH}_{4}$ gazlarından oluşmaktadır. Sonuçlar Tablo 2'de özetlenmiştir. Tablo 2'de bileşenlerin karışımdaki miktarlarının tek başlarına gazlaştırıldığında edilen gaz miktarları ve gazların bileşimleri verilmiştir.

Tablo 2. Tunçbilek linyiti ve sorgum biyokütlesinin, $900^{\circ} \mathrm{C}$ ve $0,5 \mathrm{~mL} \mathrm{dk}^{-1}$ akış hızında, tek başlarına ve birlikte gazlaștırılmaları sonucu elde edilen gazların toplam hacimleri ve bileșimleri.

\begin{tabular}{llllll}
\hline \multirow{3}{*}{$\begin{array}{l}\text { Toplam } \\
\text { Gaz }\end{array}$} & \multicolumn{4}{c}{ Gaz Kompozisyonu } \\
\cline { 2 - 6 } & Hacmi & & \%CO & $\% \mathrm{CH}_{4}$ & $\% \mathrm{CO}_{2}$ \\
\hline $\mathrm{T}^{*}$ & $1770 \pm 36$ & $68,0 \pm 1,0$ & $19,2 \pm 0,9$ & $3,8 \pm 0,1$ & $9,0 \pm 0,8$ \\
$\mathrm{~S}^{* *}$ & $360 \pm 10$ & $71,4 \pm 1,2$ & $16,0 \pm 1,1$ & $2,8 \pm 0,3$ & $9,8 \pm 0,1$ \\
$\mathrm{~T} / \mathrm{S}$ & $2730 \pm 26$ & $68,0 \pm 1,7$ & $18,3 \pm 1,0$ & $3,3 \pm 0,6$ & $10,7 \pm 0,9$ \\
\hline *Tunçbilek & & & & \\
**Sorgum & & & &
\end{tabular}

Sorgum biyokütlesinin karışımda yer alan miktarı tek başına gazlaștırıldığında $360 \mathrm{~mL}$ gaz elde edilirken kömürün karışımdaki miktarı tek başına gazlaştırıldığında elde edilen gazın hacmi 1770 mL'dir. Bu bileşenlerin birlikte gazlaştırılmasından elde edilen gaz hacmi ise $2730 \mathrm{~mL}$ olup, bu sıcaklıkta bileșenlerin tek başlarına gazlaştırıldığında elde edilen gazlarin hacimsel toplamından $600 \mathrm{~mL}$ fazladır.

$\mathrm{Bu}$ farkı yaratan pozitif etkinin, birlikte gazlaştırma prosesinin yarattığı sinerjiden kaynaklandığ düşünülmektedir. Sonuçlar hidrojen verimi açısından değerlendirildiğinde, birlikte gazlaştırma sonucu gaz bileşimindeki $\mathrm{H}_{2}$ gazı oranının $(\% 68,0)$ Tunçbilek linyitinin tek bașına gazlaștırılması sonucu elde edilenden $(\% 68,0)$ farklı olmadığı görülmektedir. Ancak, birlikte gazlaştırmanın toplam gaz hacmindeki pozitif etkisi göz önünde bulundurulduğunda, prosesten elde edilen $\mathrm{H}_{2}$ gazı miktarının birlikte gazlaştırma sonucu arttığı söylenebilir. Birlikte gazlaştırma ile Tunçbilek kömürünün tek başına gazlaşması sonucu oluşan CO oranının yaklaşık \%1'i kadar daha az CO oluşmuştur. Tek başına kömür gazlaștırmada oluşan $\mathrm{CO}_{2}$ 'nin ürün gazı karıșımındaki oranı \%9,0 iken birlikte gazlaștırmada oluşan $\mathrm{CO}_{2}$ 'nin gaz karışımındaki oranı \%10,7 olmuştur. 
Gaz bileşimlerinde $\mathrm{CH}_{4}$ gazı açısından anlamlı bir değişikliğe rastlanmamıştır. Sonuç olarak sorgum biyokütlesi ile birlikte gazlaştırma işlemi Tunçbilek kömürünün gazlaştrılmasında oluşan gaz bileşiminde herhangi belirgin bir değişikliğe sebebiyet vermemekle beraber elde gazın miktarında artış meydana getirerek pozitif etki yaratmıştır. Kömür / biyokütle karışımının biyokütle oranı, hem toplam gaz hacminde hem de karbon dönüșüm verimlerinde. Biyokütlenin yüksek reaktivitesinin bir sonucu olarak uçucu bileşenler hızla serbest radikallere dönüşür ve bu radikaller ayrışma, oksidasyon ve gazlaşma reaksiyonlarını arttırır [41]. Bu nedenle gazlaşan kömür/biyokütle karışımındaki karbon dönüşümleri biyokütle ile birlikte gazlaştırma prosesinde artma eğilimindedir ve toplam gaz hacminde artış görülmesi bu duruma ithaf edilir. Tek başına kömürü gazlaştırmak yerine birlikte gazlaștırmanın avantajı, kömürün hidrojen üretim reaksiyonlarında katalizör görevi gören biyokütlenin inorganik bileşenlerinden gelir. Dolayısı ile gazlaşan karışım içinde yer alan biyokütlenin varlığı, hidrojen üretiminde yer alan reaksiyonlardan olan su-gaz ve su gaz değişim reaksiyonlarında katalitik etki göstererek üretilen gaz karışımında hidrojen miktarının artmasına neden olmaktadir.

Tek başına kömür için, katalitik kömür gazlaştırma prosesi yüksek karbon dönüşümleri ve kok kömürü aglomerasyonunun engellenmesi açısından avantajlıdır. Biyokütle yapısında var olan inorganik içerikten kaynaklı, birlikte gazlaştırma prosesinde katalizör kullanılmaksızın da bu etkileri gözlemlemek mümkündür. Ancak prosesin iyileştirilebilmesinde herhangi bir katkı sağlanıp sağlanmayacağının değerlendirilmesi açısından, çalışmanın bu bölümünde ekstra katalizör kullanımının birlikte gazlaşmaya etkisi incelenmiştir. 0,5 mL dk-1 su akış hızı ve $900{ }^{\circ} \mathrm{C}$ sicaklıkta yaplan deneylerde, Na2CO3, $\mathrm{Fe}_{2} \mathrm{O}_{3}$ ve $\mathrm{NiCl}_{2}$ katalizörlerinin Tunçbilek/sorgum karışımının birlikte gazlaştırması üzerine etkileri araştırılmıştır. Sonuçlar Tablo 3'de özetlenmiştir.

Tablo 3. $0,5 \mathrm{~mL} \mathrm{dk}^{-1} \mathrm{su}$ akış hızı ve $900{ }^{\circ} \mathrm{C}$ sıcaklıkta, katalizör kullanılarak yapılan birlikte gazlaștırma deneylerinden elde edilen gazların toplam hacimleri ve bileșimleri

\begin{tabular}{lccccc}
\hline \multirow{2}{*}{ Katalizör } & Toplam Gaz & \multicolumn{4}{c}{ Gaz Kompozisyonu } \\
\cline { 3 - 6 } & Hacmi (mL) & $\% \mathrm{H}_{2}$ & $\% \mathrm{CO}$ & $\% \mathrm{CH}_{4}$ & $\% \mathrm{CO}_{2}$ \\
\hline- & $2730 \pm 36$ & $68,0 \pm 1,1$ & $18,3 \pm 0,9$ & $3,3 \pm 0,2$ & $10,7 \pm 0,7$ \\
$\mathrm{Fe}_{2} \mathrm{O}_{3}$ & $2810 \pm 41$ & $70,0 \pm 0,9$ & $16,9 \pm 0,7$ & $4,1 \pm 0,6$ & $9,3 \pm 0,6$ \\
$\mathrm{Na}_{2} \mathrm{CO}_{3}$ & $2945 \pm 23$ & $71,1 \pm 0,8$ & $10,4 \pm 0,6$ & $2,9 \pm 0,3$ & $15,6 \pm 1,0$ \\
$\mathrm{NiCl}_{2}$ & $2976 \pm 44$ & $70,8 \pm 0,9$ & $16,8 \pm 1,7$ & $2,1 \pm 0,1$ & $10,3 \pm 0,9$ \\
\hline
\end{tabular}

\subsubsection{Katalizör etkisi}

Tek başına kömür için, katalitik kömür gazlaştırma prosesi yüksek karbon dönüşümleri ve kok kömürü aglomerasyonunun engellenmesi açısından avantajlıdır. Biyokütle yapısında var olan inorganik içerikten kaynaklı, birlikte gazlaştırma prosesinde katalizör kullanılmaksızın da bu etkileri gözlemlemek mümkündür. Ancak prosesin iyileştirilebilmesinde herhangi bir katkı sağlanıp sağlanmayacağının değerlendirilmesi açısından, çalışmanın bu bölümünde ekstra katalizör kullanımının birlikte gazlaşmaya etkisi incelenmiştir. 0,5 mL dk-1 su akış hızı ve $900{ }^{\circ} \mathrm{C}$ sıcaklıkta yapılan deneylerde, $\mathrm{Na}_{2} \mathrm{CO}_{3}$, $\mathrm{Fe}_{2} \mathrm{O}_{3}$ ve $\mathrm{NiCl}_{2}$ katalizörlerinin Tunçbilek/sorgum karıșımının birlikte gazlaștırması üzerine etkileri araştırılmıştır. Sonuçlar Tablo 3'de özetlenmiştir.

Birlikte gazlaştırmanın kömür gazlaştırma prosesinde yarattığı pozitif etki oldukça belirgindir. Katalizör kullanımı ise bu pozitif etkiyi bir miktar daha arttırarak gazlaşma prosesini daha verimli hale getirmiştir. Ayrıca kullanılan tüm katalizörler ürün gazı içeriğindeki $\mathrm{H}_{2}$ yüzdesini arttırmıştır (\%2-\%3). En yüksek gaz hacmi $\mathrm{Na}_{2} \mathrm{CO}_{3}$ ve $\mathrm{NiCl}_{2}$ katalizörünün kullanıldığı deneylerden elde edilmiştir. Bu durum $700{ }^{\circ} \mathrm{C}$ 'nin üzerindeki sıcaklıklarda elde edilen ürün gazı içeriğinin $\mathrm{CO}$ ve $\mathrm{H}_{2}$ yönünden zengin olmasına neden olmuştur. $\mathrm{NiCl}_{2}$ varlığında $\mathrm{H}_{2}$ gazında $\% 2,8$ 'lik artış gözlenmiştir.

Karıșımdaki \%CO oranı, katalizör kullanılmaksızın yapılan gazlaștırmaya kıyasla az olmakla birlikte, diğer katalizörler eşliğinde yapılan gazlaștırmalara nazaran daha yüksektir. $\mathrm{Na}_{2} \mathrm{CO}_{3}$ eşliğinde yapılan gazlaștırmada ürün gazındaki $\% \mathrm{H}_{2}$ değeri $\% 71,1$ ile en yüksek değerde iken, \%CO oranının katalizörsüz gazlaştırmaya oranla gazın yaklaşık \%8 azaldığı ve $\% \mathrm{CO}_{2}$ oranının ise yaklaşı $\% 5$ arttığ gözlemlenmektedir. Sodyum gibi alkali metaller, gazlaşma esnasında büyük aromatik halka oluşumlarının ve yüksek molekül ağırlıklı uçucu hidrokarbonların oluşumunu engeller. Dolayısı ile bu ürünlerin düşük molekül ağırlıklı gazlaşma ürünlerine dönüşür. Bu durum gazlaşma verimine toplam gaz hacmi açısından pozitif etki sağlar [42]. $\mathrm{Fe}_{2} \mathrm{O}_{3}$ eşliğinde yapılan gazlaştırma sonrası ürün içeriğindeki $\mathrm{H}_{2}$ gazı katalizörsüz gazlaștrmaya oranla \%2 daha fazladır. Kömür pirolizi esnasında açığa çıkan hidrokarbonların buhar reformlama reaksiyonlarının hızları uygun bir oksijen verici varlığında artabilmektedir. $\mathrm{FeO}-\mathrm{Fe}_{2} \mathrm{O}_{3}$ dönüșümü için yapılan termodinamik analizler, bu dönüşümün sentez gazının $\mathrm{H}_{2}$ gazına dönüşümünde etkin olan su gaz değişim reaksiyonunu destekleyecek ideal entalpiye sahip olduğunu göstermiştir [43]. Ancak, $\mathrm{H}_{2}$ gazı da bu koşullarda $\mathrm{Fe}_{2} \mathrm{O}_{3}$ tarafından eş zamanlı olarak oksitlenmektedir ve dolayısı ile hidrokarbon dönüşümleri ile artan gaz miktarı içeriğindeki $\mathrm{H}_{2}$ gazının bir kısmı $\mathrm{Fe}_{2} \mathrm{O}_{3}$ tarafından oksitlenerek hem hidrojen gazının gaz karıșımdaki oranının azalmıș olması hem de oluşan toplam gaz hacminin diğer katalizörlere kıyasla düşük olması muhtemeldir. $\mathrm{Fe}_{2} \mathrm{O}_{3}$ katalizörü ayrıca $\mathrm{CO}-\mathrm{CO}_{2}$ dönüşümlerini de destekleyecek reaksiyonlarda yer alarak gaz karışımı içerisindeki $\mathrm{CO}$ oranının azalmasına ve $\mathrm{CO}_{2}$ oranının ise artmasına neden olmuştur. 


\subsection{Sorgum hidrolizatı ile birlikte gazlaştırma}

Çalışmanın bu bölümünde Tunçbilek linyiti katı sorgum biyokütlesi yerine sub-kritik su ortamında hidrolizi gerçekleștirilmiş sorgum hidrolizatı ile birlikte gazlaştırılmıștır. Deneyler gazlaştırma sıcaklığına ulașmıș sisteme, ișlenmemiș biyokütle içeriğinde eş değer organik karbon içeren hidroliz çözeltisinin, $0,5 \mathrm{~mL} \mathrm{dk^{-1 }}$ akış hızında gönderilmesi yoluyla gerçekleştirilmiştir. Sonuçlar elde edilen toplam gaz hacmi ve gazın içeriği açısından değerlendirilerek ișlenmemiş biyokütle ile yapılan birlikte gazlaştırma deneyleri sonuçları ile kıyaslanmıştır (Tablo 4).

Tablo 4. Tunçbilek linyitinin sorgum hidrolizatı ile $0,5 \mathrm{~mL}$ $\mathrm{dk}^{-1}$ hidrolizat akıș hızı ve $900^{\circ} \mathrm{C}$ sıcaklıkta birlikte gazlaștırmasından elde edilen gaz ürünlere ait sonuçlar

\begin{tabular}{llcccc}
\hline Katalizör & Toplam Gaz & \multicolumn{4}{c}{ Gaz Kompozisyonu } \\
\cline { 3 - 6 } & Hacmi $(\mathrm{mL})$ & $\% \mathrm{H}_{2}$ & $\% \mathrm{CO}$ & $\% \mathrm{CO}_{2}$ & ${ }_{0} \mathrm{CH}_{4}$ \\
\hline $\mathrm{T}$ & $1770 \pm 36$ & $68,0 \pm 1,0$ & $9,0 \pm 0,6$ & $19,2 \pm 0,9$ & $3,8 \pm 0,1$ \\
$\mathrm{~T} / \mathrm{S}$ & $2430 \pm 28$ & $68,0 \pm 1,3$ & $10,7 \pm 0,8$ & $18,3 \pm$ & $3,0 \pm 1,1$ \\
& & $70,0 \pm 1,1$ & $9,3 \pm 05$ & $16,6 \pm 0,7$ & $4,1 \pm 0,1$ \\
\hline
\end{tabular}

*Sorgum hidrolizatı

Sorgum hidrolizatı ile yapılan gazlaştırmada toplam gaz hacmi $(2810 \mathrm{~mL})$, Tunçbilek linyitinin hem tek başına $(1770 \mathrm{~mL})$, hem de öğütülmüş katı sorgum biyokütlesi ile birlikte gazlaștırılmasından elde edilen (2430 $\mathrm{mL}$ ) toplam gaz hacimlerinden belirgin bir şekilde daha fazladır. Ayrıca, sorgum biyokütle hidrolizatı ile yapılan birlikte gazlaștırmada gaz bileşimindeki \% CO ve $\% \mathrm{CO}_{2}$ oranı (sırasıyla \% 9,3 ve \% 16,6) katı biyokütle ile yapılan birlikte gazlaştırmadan elde edilen $\% \mathrm{CO}$ ve $\% \mathrm{CO}_{2}$ oranlarına nazaran (sırasıyla $\% 10,7$ ve \% 18,3) azalmıștır ve $\mathrm{H}_{2}$ oranı ise \% 2'lik bir artış göstermiştir. Lignoselülozik materyallerde selüloz, hemiselüloz ve lignin olmak üzere üç ana bileşen mevcuttur. Bu bileşenlerden selüloz yüksek derecede düzenli $(\% 60)$ kristal yapı özelliği gösterir ve suda çözünmez. Hemiselüloz ise polimerizasyon derecesi selüloza göre daha düşük dallanmış bir yapıya sahiptir. Lignin ise üç boyutlu aromatik amorf yapıya sahiptir ve lignoselülozik madde yapısının en hidrofobik bileșenidir. Biyokütlenin bu karmaşık kimyasal yapısı, hidroliz işlemi parçalanarak ile suda çözünebilir oksijenli bileşiklere (şekerler, şeker alkolleri ve gliserol vb.) dönüştürülür. $\mathrm{Bu}$ çözündürme ön işlemi sonucu oluşan nispeten daha küçük yapılara sahip moleküllerin gaz ürünlere dönüşümü, biyokütlenin işlenmemiş karmaşı k yapısına nazaran daha kolay bir hale gelebilmektedir. Tunçbilek linyitinin sorgum hidrolizatı ile yapılan gazlaştırmasında elde edilen gaz ürün miktarının daha fazla olması bu duruma atfedilmiştir.

Gazlaştırma işlemleri sonrasında toplanan sıvı ürünlerin GC/MS analizleri gerçekleștirilerek ürün dağılımları incelenmiștir. Ortak olarak tüm gazlaştırma deneylerinden sonra edilen sıvı ürünler yüksek konsantrasyonlarda fenol ve türevleri ile alifatik hidrokarbonlar içermektedir. Sorgum hidrolizatının birlikte gazlaştırma öncesi yapılan GCMS analizleri sonucu içeriğinde özellikle ligninden kaynaklanan parçalanma ürünleri olan, fenol, 4methoxy fenol, 3-etil fenol, 4-asetil-1,3,5trimetilpirazol, 2,6-dimetoksi-fenol, vanilin, phidroasetofenon, bütilftalat bileşiklerine rastlanmıştır. İşlenmemiş sorgum ve sorgum hidrolizatı ile yapılan birlikte gazlaştırma deneyleri sonrası sıviların GC-MS spektrumlarının karşılaştırılması Şekil 2'de verilmektedir.

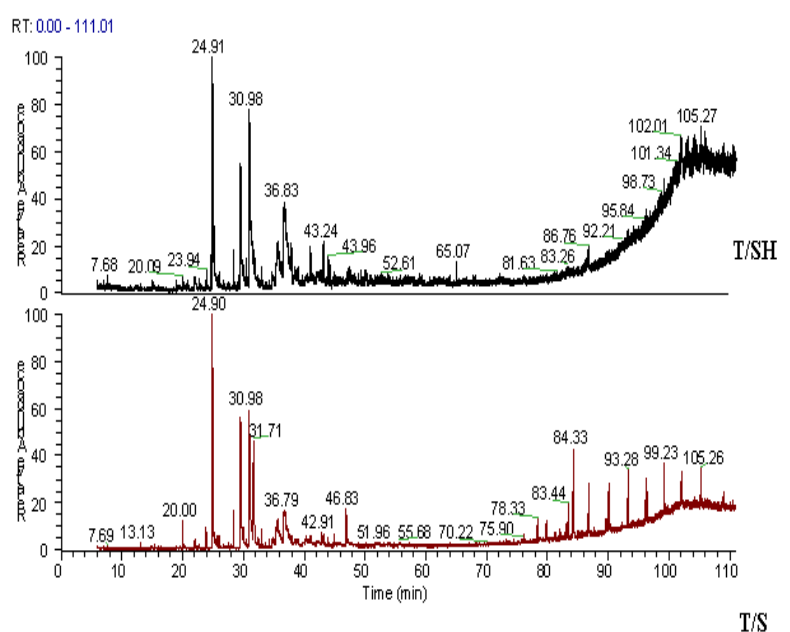

Şekil 2. Tunçbilek linyitinin sorgum biyokütlesi ve sorgum biyokütle hidrolizatı ile yapılan birlikte gazlaştırma deneylerinden sonra rezervuarda toplanan sıviların GC/MS analizlerinin karşılaștırılması.

İşlenmemiş sorgum ile yapılan gazlaştırma sonrası sıvı içeriğinde fenol ve türevi bileșenlerin yanı sıra 2izopropil-10-metil fenantren $(\mathrm{dk}$ 84,33), 3hekzilheptadekan ( $\mathrm{dk}$ 86,86), 3-Etil-5(2etilbütil)oktadekan (dk 90,13), 9-hekzil heptadekan $(93,23)$ gibi karmaşık yapılı büyük moleküllere rastlanırken, hidrolizat ile yapılan deneylerden toplanan sıvı içeriğinin yalnızca fenol ve türevlerinden oluştuğu görülmektedir (dk. 24,90 fenol; dk. 30,98 3-metil fenol; dk. 31,71 4-etilfenol) (Şekil 2). Bu durum, işlenmemiş katı biyokütle yerine çözündürülmüş biyokütle kullanılarak yapılan gazlaştırma deneylerinde gaz ürünlere dönüşemeden kondense olan büyük moleküllü karmaşık yapılı hidrokarbonlar yerine gaz ürüne dönüșebilen nispeten küçük moleküllü yapıların gazlaşma reaksiyonlarında yer aldığı savını desteklemektedir.

\section{Sonuç}

Bu çalışmada Tunçbilek linyiti ögütülmüş katı sorgum biyokütlesi ve sub-kritik su koşullarında hidroliz edilmiş sorgum hidrolizatı ile birlikte gazlaştırılmıştır. Birlikte gazlaștırma deneylerinden elde edilen toplam gaz miktarı, Tunçbilek linyitinin ve sorgum biyokütlesinin aynı koşullarda tek başlarına gazlaştırılmalarından elde edilenden daha fazla olduğu gözlemlenmiştir. Sorgum ile yapılan birlikte gazlaștırma deneylerinde katalizör kullanımı hem 
elde edilen toplam gaz hacimlerinde hem de gazların bileşimindeki hidrojen gazı oranlarında artışa neden olmuştur ve gazlaştırmada gaz miktarları açısından en etkin katalizörler $\mathrm{Na}_{2} \mathrm{CO}_{3}$ ve $\mathrm{NiCl}_{2}$ olarak belirlenmiştir. Sorgum hidrolizatı ile yapılan birlikte gazlaștırma deneylerinde elde edilen toplam gaz hacmi (2810 mL), ögütülmüş katı sorgum biyokütlesi ile yapılan birlikte gazlaştırmadan elde edilen toplam gaz hacminden (2430 $\mathrm{mL}$ ) daha fazla olmuştur. Bu durum biyokütlenin suda çözündürülmesi sonucu elde edilen hidrolizatın daha kolay gazlașabilen içeriğe sahip olduğunu göstermiștir. Kömürle birlikte yapılan gazlaştırma deneylerinde sorgumun sinerjik etki yaptığı gözlemlenmiștir.

\section{Teşekkür}

$\mathrm{Bu}$ çalışma Çukurova Üniversitesi Bilimsel Araştırmalar ve Projeler Birimi (BAP) tarafından FDK-2015-3741 no'lu proje ile desteklenmiştir.

\section{Kaynakça}

[1] World Energy Resources 2016. World Energy Council https://www.worldenergy.org/wpcontent/uploads/2016/10/World-Energy-

Resources-Full-report-2016.10.03.pdf (Erişim tarihi 10.10.2018).

[2] World Energy Outlook, 2016. https://www.iea.org/media/publications/weo/ WE02016, Chapter1.pdf (Erişim tarihi: 10.04.2017).

[3] Minchener, J.A. 2005. Coal gasification for advanced power generation. Fuel, 17, 2222-35.

[4] Mallick, D., Mahanta, P., Moholkar, V.S. 2017. Cogasification of coal and biomass blends: Chemistry and engineering. Fuel, 204, 106-28.

[5] Veraa, M.J., Bell, A.T. 1978. Effect of alkali metal catalysts on gasification of coal char. Fuel, 57(4), 194-200.

[6] Moore, T.A., Pearce, S. 2006. Hydrogen from coal. International Journal of Coal Geology, 65 (3-4), 171-2.

[7] Stiegel, G.J., Ramezan, M. 2006. Hydrogen from coal Gasification:An economical pathway to a sustainable future. International journal of coal geology, 65 (3-4), 173-190.

[8] Veraa, M.J., Bell, A.T. 1978. Effect of alkali metal catalysts on gasification of coal char. Fuel, 57 (4), 194-200.

[9] Masnadi, M.S., Grace, J.R., Bi, X.T., Lim, C.J., Ellis, N., Li, Y.H., Watkinson, A.P. 2015. From coal towards renewables: catalytic/synergistic effects during steam co-gasification of switchgrass and coal in a pilot-scale bubbling fluidized bed. Renew Energy, 83, 918-930.
[10] Masnadi, M.S., Grace, J.R., Bi, X.T., Lim, C.J., Ellis, N. 2015. From fossil fuels towards renewables: inhibitory and catalytic effects on carbon thermochemical conversion during cogasification of biomass with fossil fuels Appl. Energy, 140, 196-209.

[11] Mckee, D.W. 1983. Mechanisms of alkali metal catalysed gasification of carbon. Fuel, 62, 170175.

[12] Mckee, D.W., Chatterji, D. 1975. The catalytic behavior of alkali meral carbonates and oxides in graphite oxidation reactions. Carbon, 13, 381390.

[13] Pan, Y.G., Velo, E., Roca, X., Manya, J.J., Puigjaner, L. 2000. Fluidized-bed co-gasification of residual biomass/poor coal blends for fuel gas production. Fuel, 79(11), 1317-1326.

[14] Sjöstroöm, K., Chen, G., Yu, Q., Brage, C., Rosen, C. 1999. Promoted reactivity of char in cogasification of biomass and coal: synergies in the thermochemical process. Fuel, 78 (10), 11891194.

[15] Brown, C.R., Liu, K., Norton, G. 2000. Catalytic effects observed during the co-gasification of coal and switchgrass. Biomass Bioenergy, 18 (6), 499-506.

[16] Howaniec, N., Smolinski, A., Stanczyk, K., Pichlak, M. 2011. Steam co-gasification of coal and biomass derived chars with synergy effects as an innovative way of hydrogen-rich gas production. Int J Hydrogen Energy, 36(22), 14455-14463.

[17] Ren, H.J., Zhang, Y.Q., Fang, Y.T., Wang, Y. 2012. Co-gasification properties of coal char and biomass char. Journal of Fuel Chemistry and technol, 40 (2), 143-148.

[18] Howaniec, N., Smolinski, A. 2013. Steam cogasification of coal and biomass- synergy in reactivity of fuel blends char. Int J Hydrogen energy, 38(36), 16152-16160.

[19] Rizkiana, J., Guan, G., Widayatno, W.B., Hao, X., Huang, W., Tsutsumi, A., Abudula, A. 2014. Effect of biomass type on the performance of cogasification of low rank coal with biomass at relatively low temperatures. Fuel, 134, 414-419.

[20] Ellis, N., Masnadi, S.M., Roberts, D.G., Kochanek, M.A., Ilyushechkin, A.Y. 2015. Mineral matter interactions during co-pyrolysis of coal and biomass and their impact on instrinsic char cogasification reactivity. Chemical Engineering Journal, 279, 402-408.

[21] Brar, J.S., Singh, K., Wang, J., Kumar, S. 2012. Gasification of Coal and Biomass: A review. Int J Forestry Research, 363058:10. 
[22] Kezhong, L., Zhang, R., Bi, J. 2010. Experimental study on syngas production by cogasification of coal and biomass in a fluidized bed. Int J Hydrogen Energy, 35, 2722-2726.

[23] Velez, F.J., Chejne, F., Valdes, C.F., Emery, E.J., Londono, C.A. 2009. Co-gasification of Colombian coal and biomass in fluidized bed: An experimental study. Fuel, 88(3), 424-430.

[24] Wang, L.Q., Chen, Z.S. 2013. Gas Generation by co-gasification of biomass and coal in an autothermal fluidized bed. Applied Thermal Engineering, 59, 278-282.

[25] Xu, Q., Pang, S., Levi, T. 2015. Cogasification of blended coal-biomass in an air/steam BFB gasifier: Experimental investigation and model validation. AIChE Journal, 61(5), 1639-1647.

[26] Jeong, H.J., Hwang, I.S., Hwang, J. 2015. Cogasification of bituminous coal-pine sawdust blended char with $\mathrm{H} 20$ at temperatures of 750$850{ }^{\circ} \mathrm{C}$. Fuel, 156, 26-29.

[27] Song, Y.C., Ji, M.S., Feng, J., Li, W.Y. 2015. Product distribution from co-gasification of coal and biomass in a fluidized-bed reactor. Energy sources, Part A: Recovery, utilization and Environmental Effects, 37 (23), 2550-2558.

[28] Pinto, F., Franco, C., Andre', R.N., Tavares, C., Dias, M., Gulyurtlu, I., Cabriata, I. 2003. Effect of experimental conditions on $\mathrm{CO}$ gasification of coal, biomass and plastics wastes with air/steam mixtures in a fluidized bed system. Fuel, 82, 1967-1976.

[29] Wang, L.Q., Chen, Z.S. 2013. Experimental studies on $\mathrm{H} 2$-rich gas production by cogasification of coal and biomass in an intermittent fluidized bed reactor. Advance materials research, 724-725, 1127-1131.

[30] Tursun, Y., Xu, S., Wang, G., Wang, C., Xiao, Y. 2015. Tar formation during co-gasification of biomass and coal under different gasification condition.Journal of analytical and applied Pyrolysis, 111, 191-199.

[31] Kumabe, K., Hanaoka, T., Fujimoto, S., Minowa, T., Sakanishi, K. 2007. Co-gasification of woody biomass and coal with air and steam. Fuel, 86 (5-6), 684-689.

[32] Collot, A.G., Zhuo, Y., Dugwell, D.R., Kandiyoti, R. 2003. Co-pyroysis and co-gasification of coal and biomass in bench scale fixed-bed and fluidized bed system. Fuel, 82(15-17), 1967-1976.

[33] Valdés, C.F., Marrugo, G., Chejne, F., Montoya, J.I., Gomez, C.A. 2015. Pilot-scale fluidized-bed cogasification of palm kernel shell with subbituminous coal. Energy Fuels, 29(9),5894-5901.

[34] Che, D., Sun, Y., Li, S. 2016. Exergy analysis of cogasification process of pine sawdust and lignite in fluidized bed. Taiyangneng Xuebao/Acta Energiae Solaris Sinica, 37(4), 968-973.

[35] Fermoso, J., Arias, B., Plaza, M.G., Pevida, C., Rubiera, F., Pis, J.J. 2009. High-pressure COgasification of coal with biomass and petroleum coke. Fuel Process Technol, 90, 926-958.

[36] Howainec, N., Smolinski, A. 2014. Effect of fuel blend composition on the efficiency of hydrogen -rich gas production in co-gasification of coal and biomass. Fuel, 128, 442-450.

[37] Lapuerta, M., Hernandez, J.J., Pazo, A., Lopez, J. 2008. Gasification and co-gasification of biomass wastes; effect of the biomass origin and the gasifier operating conditions. Fuel Process Technol, 89, 828-837.

[38] Li, K., Zhang, R., Bi, J. 2010. Experimental study on syngas production by co-gaisification of coal and biomass in a fluidized bed. Int J Hydrogen energy, 35, 2722-2726.

[39] Meryemoğlu, B., Hesenov, A., Irmak, S., Atanur, O., Erbatur, O. 2010. Aqueous phase reforming of biomass using various types of supported precious metal and raney-nickel catalysts for hydrogen production. Int J Hydrogen Energy, 35, 12580-12587.

[40] Seçer, A., Küçet, N., Fakı, E., Hasanoğlu, A. 2018. Comparison of co-gaisification efficiencies of coal, lignocellulosic biomass and biomass hydrolysate for high yield hydrogen production. Int J Hydrogen energy, 43, 21269-21278.

[41] Huang, J., Yitian, F., Chen, H., Wang, Y. 2003. Coal gasification characteristic in a pressurized fluidized bed, Energy Fuels, 17, 1474-1479.

[42] Ding, L., Zhou, Z., Guo, Q., Yu, G. 2015. Catalytic effects of $\mathrm{Na}_{2} \mathrm{CO}_{3}$ additive on coal pyrolysis and gasification. Fuel, 142, 134-144.

[43] Mondal, K., Piotrowski, K., Dasgupta, D., Hippo, E., Wiltowski, T. 2005. Hydrogen from coal in a single step. Industrial \& Engineering Chemistry Research, 44(15), 5508-5517. 